\title{
USABILIDADE DE DISPOSITIVOS DE REALIDADE VIRTUAL APLICADA À AVALIAÇÃO PRÉ-PROJETO
}

\author{
PINHEIRO, Pedro Sávio Jobim \\ Universidade de São Paulo, e-mail: pedro.savio.pinheiro@usp.br \\ ORNSTEIN, Sheila Walbe \\ Universidade de São Paulo, e-mail: sheilawo@usp.br \\ SHIMOMURA, Alessandra Rodrigues Prata \\ Universidade de São Paulo, e-mail: arprata.shimo@gmail.com
}

\begin{abstract}
RESUMO
Este artigo é parte de um mestrado em desenvolvimento e tem por objetivo avaliar, de forma exploratória, a usabilidade do equipamento de Realidade Virtual Oculus Rift para a avaliação de projeto de arquitetura. Os procedimentos metodológicos utilizados para o desenvolvimento do estudo foram levantamentos in situ aplicados no edifício da Pinacoteca do Estado, na cidade de São Paulo realizados em duas etapas: a primeira com o Pátio Interno Norte modelado e vivenciado virtualmente, por meio do uso óculos de Realidade Virtual, e a segunda parte com questionários aplicados no pátio construído. Os resultados alcançados mostram que, embora os Displays Visualmente Acoplados (DVAs) sejam de fácil usabilidade, suas configurações e formas de utilização podem alterar a percepção dos usuários. O artigo conclui que a Realidade Virtual pode ser usada como ferramenta para Avaliação Pré-Projeto (APP) sem causar altos níveis de desconforto aos usuários e contribuindo para gestão da qualidade de projeto, mas ainda possui limitações ao uso recorrente durante a prática de projeto.
\end{abstract}

Palavras-chave: Realidade Virtual, Avaliação Pré-Projeto, Usabilidade.

\begin{abstract}
This article is part of a master's degree in progress and aims to evaluate, on an exploratory way, the usability of Oculus Rift for the evaluation of architectural design. The methodological procedures used for the development of this study were questionnaires applied in Pinacoteca do Estado in the city of São Paulo in two stages: the first one in the virtual North Patio, through the use of Virtual Reality goggles, and the second part with questionnaires applied in the real patio. The results show that although Head Mounted Displays (HMDs) are easy to use, their configuration can change users' perceptions. The article concludes that Virtual Reality can be used as a tool for Pre-Design Evaluation (PDE) with no high level of discomfort contributing to design quality management, but still has limitations to be frequently used during the design process.
\end{abstract}

Keywords: Virtual Reality, Pre-design Evaluation, Usability.

\section{INTRODUÇÃO}

O conceito de qualidade na arquitetura, segundo Voordt e Wegen (2005) se relaciona à satisfação a determinados requisitos de desempenho. Por essa definição, o usuário dos ambientes construídos desempenha papel central para a qualidade do processo de projeto em arquitetura, sendo de extrema

PINHEIRO, P. S. J.; ORNSTEIN, S. W.; SHIMOMURA, A. R. P. Usabilidade de dispositivos de realidade virtual aplicada à avaliação pré-projeto. In: SIMPÓSIO BRASILEIRO DE QUALIDADE DO PROJETO NO AMBIENTE CONSTRUÍDO, 6., 2019, Uberlândia. Anais... Uberlândia: PPGAU/FAUeD/UFU, 2019. p. 1419-1430. DOI https://doi.org/10.14393/sbqp19127. 
importância que este seja contemplado em avaliações contínuas nas etapas de projeto (FABRíCIO; ORNSTEIN, 2010, p. 8).

São procedimentos metodológicos voltados à gestão de qualidade de projeto, a avaliação de desempenho e de satisfação dos usuários, tanto nas fases de projeto, incluindo a de pré-projeto, como nas fases de uso e manutenção, pois esses mecanismos retroalimentam decisões sobre diretrizes de projeto e programas de manutenção e retrofit no caso de edifícios já em UsO (FEDERAL FACILITIES COUNCIL, 2001; ORNSTEIN; ONO, 2010 apud FABRICIO et al., 2010).

Avaliações de desempenho de ambientes construídos buscam mitigar falhas e conciliar expectativas de projetistas e usuários em todas as fases de projeto, tornando possível o desenvolvimento de bancos de dados de boas práticas que possam subsidiar programas de manutenção dos próprios casos estudados e, também, em futuros projetos (FABRICIO et al., 2010, p. 7). A comunicação recorrente na prática profissional entre arquiteto e usuário em fase de projeto ainda se baseia em linguagens que muitas vezes não são de fácil leitura aos usuários finais: desenhos técnicos, diagramas e listas de especificações. Norouzi et al. (2014, p. 636) destacam que os problemas de comunicação entre arquiteto e usuário podem ter duas origens: social e técnica e que uma possível estrutura para gerenciar problemas de comunicação de natureza social é o desenvolvimento de técnicas para permitir a participação dos usuários em cada etapa do processo de projeto (SARVARAZADEH et al. apud NOROUZl et al., 2014, p. 637).

O objeto de estudo deste artigo é a usabilidade do dispositivo de Realidade Virtual Oculus Rift como ferramenta de comunicação entre arquitetos e usuários durante a Avaliação Pré-Projeto (APP).

Segundo Jerald (2016) apud Souza, Imai e Azuma (2018, p. 25), a Realidade Virtual (RV) é caracterizada por um ambiente digital que pode ser experimentado de forma interativa pelo ser humano, simulando o ambiente construído.

A RV, como mecanismo de desenvolvimento de projeto, pode ser importante simulador de novos espaços e fonte confiável da reação de projetistas, usuários e clientes (KOWALTOWSKI, 2013, p. 169). Essa ferramenta apresenta potencial de uso durante a APP, quando, segundo Benevente (2002, p. 43), por meio da correção e prevenção de falhas no desempenho de um dado ambiente, é possível gerar informações imediatas de adequação do projeto em andamento.

\section{PROCEDIMENTOS METODOLÓGICOS}

O estudo de caso escolhido para a realização do levantamento in situ foi o Pátio Interno Norte da Pinacoteca do Estado, localizado na Praça da Luz, $\mathrm{n}^{\circ}$ 02. Os questionários de avaliação do ambiente virtual e do Dispositivo Visualmente Acoplado (DVA), foram aplicados em dois momentos distintos: o primeiro em um pré-teste, realizado no dia 3 de fevereiro de 2019 com 25 visitantes voluntários da Pinacoteca, no período de 10h30 às 17h30; O segundo nos demais finais de semana do mês de fevereiro de 2019, das 11 h da manhã às 18h, com 100 usuários. O público-alvo desta pesquisa foram adultos leigos à 
arquitetura, entre 18 e 60 anos, que não possuíssem problemas cardíacos ou de visão.

A pesquisa empírica, uma vez que tem relação com seres humanos, foi submetida à apreciação na Plataforma Brasil e aprovação pelo Comitê de Ética em Pesquisa da Escola de Artes, Ciências e Humanidades da Universidade de São Paulo, sob o Certificado de Apresentação para Apreciação Ética (CAAE) número: 00704818.2.0000.5390 e parecer número 3.022.330.

\subsection{Modelagem}

O modelo utilizado para a aplicação dos questionários de avaliação do ambiente virtual foi desenvolvido a partir de desenhos técnicos do projeto do edifício da Pinacoteca em nível gráfico semelhante à fase de Estudo Preliminar por meio da utilização dos programas Trimble Sketchup 2018 e Unreal Engine 20.3 e do Dispositivo Visualmente Acoplado Oculus Rift. Para a conversão de desenhos técnicos em ambientes virtuais são necessários quatro procedimentos: modelagem tridimensional em Trimble Sketchup, exportação do modelo tridimensional de Trimble Sketchup para Unreal Engine, adequação do modelo tridimensional para Realidade Virtual em Unreal Engine, utilizando o modelo pré-configurado de First Person Character ${ }^{l}$ e conexão com o DVA Oculus Rift.

Para o isolamento do objeto de estudo foi necessária a modelagem dos ambientes adjacentes ao pátio interno norte para que se reproduzisse a dinâmica de sombras de forma semelhante ao ambiente construído. Nesta modelagem, considerou-se como ambientes adjacentes ao pátio os corredores perimetrais do pátio e algumas salas de exposição contíguas ao ambiente de estudo. Portanto, após os ambientes adjacentes, foram modeladas paredes fictícias para que os usuários, configuradas para reagirem a colisões, em modo de utilização First Person Character, não saíssem do modelo.

Para o modelo em avaliação, foi utilizada apenas iluminação natural e os materiais foram importados diretamente do Trimble Sketchup 2018, apenas com alterações de brilho, reflexo e textura. Para a utilização do Oculus Rift, DVA escolhido para os procedimentos de avaliação dos ambientes construídos, a configuração dos sensores, controles e sensores do dispositivo, além do cadastramento do espaço disponível para a utilização do aparelho, é necessário por questão de segurança do usuário, pois este evita possíveis colisões do usuário com o ambiente construído durante a utilização do DVA.

\subsection{Desenvolvimento de formulário de questionário}

O questionário para avaliação do ambiente virtual foi baseado em questionários de Avaliação Pós-Ocupação (APO), que, segundo Ono et al. (2018, p. 25), é uma forma de abordagem composta por múltiplos métodos para a avaliação do desempenho do ambiente construído no decorrer do uso. As APOs fornecem respostas às decisões de projeto e ao desempenho do

\footnotetext{
1 First Person Character é um modelo pré-configurado no software Unreal Engine, que permite que o usuário fique imerso e caminhe livremente pelos ambientes modelados de forma semelhante ao videogame de primeira-pessoa.
} 
edifício resultante, constituindo-se como procedimento metodológico para o desenho de melhores edifícios no futuro. O desempenho do edifício é considerado quanto ao seu efeito sobre a saúde dos usuários, segurança, desempenho funcional e conforto psicológico / físico.

A avaliação de ambientes virtuais foi feita, portanto, por um questionário contemplando respostas de múltiplas escolhas, escala de valores e também perguntas abertas (textos curtos) baseadas nos modelos de questionários de APO. Os questionários foram preenchidos pelo pesquisador, a partir das respostas verbais dos usuários, uma vez que os usuários estavam imersos no ambiente virtual.

O questionário pré-teste teve por objetivo a aferição do tempo para a sua aplicação, além de sua verificação quanto à inteligibilidade para leigos (ORNSTEIN, 2016, p. 191). Com base no pré-teste também foi possível avaliar, em primeira instância, níveis de usabilidade do equipamento em estudo.

As primeiras perguntas do questionário pré-teste foram agrupadas em três categorias: perguntas contextuais, perguntas de seleção de público e perguntas de caracterização de público.

O primeiro grupo de perguntas foi desenvolvido para caracterizar o contexto dos usuários quando da aplicação dos questionários: Data, Hora de início, Condições Climáticas e Sensação Térmica.

O segundo grupo de perguntas teve por objetivo verificar a elegibilidade do público para a realização dos questionários. Ao considerar que o propósito da pesquisa é o desenvolvimento de procedimentos metodológicos para avaliação de ambientes virtuais, o público-alvo teve de atender a alguns requisitos.

O primeiro requisito se refere à idade. $O$ público-alvo desta pesquisa foi restrita a indivíduos adultos, entre 18 e 65 anos, por esta ser a faixa de idade que melhor se adapta à tecnologia.

O segundo fator de elegibilidade de público-alvo se refere ao fato de serem usuários leigos à construção civil ou arquitetura. Segundo Cialone et al. (2017, p. 524), arquitetos parecem relacionar-se com uma conceituação espacial diferente [quando comparado a outras profissões], manifestada através de um modo sistematicamente contrastante de falar sobre o espaço de trabalho. Já Julean (2016, p. 2) demonstrou, em um estudo comparativo entre estudantes de ensino superior, que, no caso de edifícios, há uma distinção muito clara entre as respostas de percepção dadas por estudantes de arquitetura e os estudantes dos demais cursos. Por esta pesquisa se tratar de um estudo que visa extrapolar procedimentos de avaliação de ambientes construídos a outros casos de projeto, que geralmente são realizados junto ao público leigo, foi necessário restringir a participação de arquitetos como usuários na aplicação de questionários.

O primeiro grupo de questões de usabilidade visou verificar se há algum tipo de limitação à utilização do equipamento. Ainda que os públicos mais sensíveis à utilização de DVAs sejam os públicos infantil e idoso, há casos também de pessoas adultas que apresentam desconfortos, tais como tonturas, desorientação, dor de cabeça, náusea, mal-estar, dor nos olhos, cansaço ou 
sonolência ${ }^{2}$. Portanto, as duas primeiras perguntas do questionário visavam verificar o conforto na utilização da ferramenta de modo preliminar. As questões preliminares foram:

1. Você sente algum tipo de desconforto: Tontura/ Desorientação/ Dor de cabeça/ Náusea/ Mal-estar/ Dor nos olhos/ Cansaço ou sonolência?

2. O aparelho se encaixa de forma confortável em sua cabeça? Sim/Não

3. A projeção está nítida? Sim/ Não

Ao final da aplicação dos questionários, os usuários responderam a perguntas de usabilidade, que visavam verificar se, após a utilização dos óculos, os usuários sentiram algum tipo de desconforto, se o dispositivo se encaixou confortavelmente no rosto durante sua utilização e se a projeção ficou nítida durante todo o procedimento. As perguntas finais foram idênticas às aplicadas no início do procedimento e visaram comparar os níveis de conforto do equipamento no início dos procedimentos e no final dos mesmos.

\subsection{Montagem da estação de trabalho}

Para a realização do levantamento in situ, foi necessária a montagem de uma estação de trabalho, contando com computador, os Óculos de Realidade Virtual Oculus Rift, composto por um DVA, dois sensores e dois controles remotos, TCLEs para assinatura prévia pelos usuários, questionários impressos e um medidor de temperatura e pressão (Figura 1).

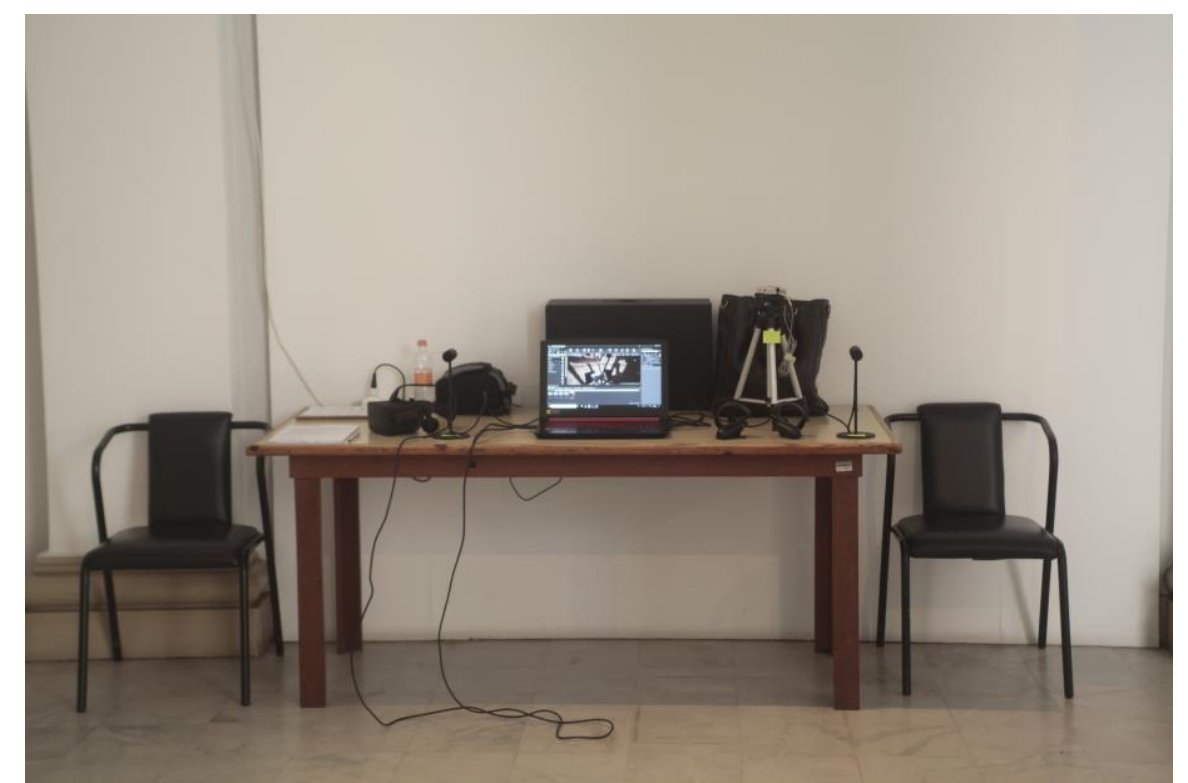

Figura 1 - Estação de trabalho necessária para levantamento in siłu com usuários voluntários -

Fonte: Autor

Para a realização dos procedimentos com utilização de DVAs de Realidade Virtual é necessária conexão com fonte de energia para a correta reprodução de imagem e espaço físico livre de, pelo menos, $2 \times 2 m$ para utilização dos óculos pelos usuários. Antes do início das atividades, o espaço

${ }^{2}$ Cf. <www.oculus.com/support>. Acesso em: 27 de jan. 2018. 
disponível para as atividades é cadastrado virtualmente no DVA, para que os usuários utilizem o equipamento de forma segura.

\subsection{Aplicação de questionários}

A aplicação dos questionários foi realizada em duas etapas: Primeiramente, os usuários voluntários participantes da pesquisa foram convidados a experimentar os óculos de Realidade Virtual e, posteriormente, a avaliar comparativamente os ambientes virtual e construído.

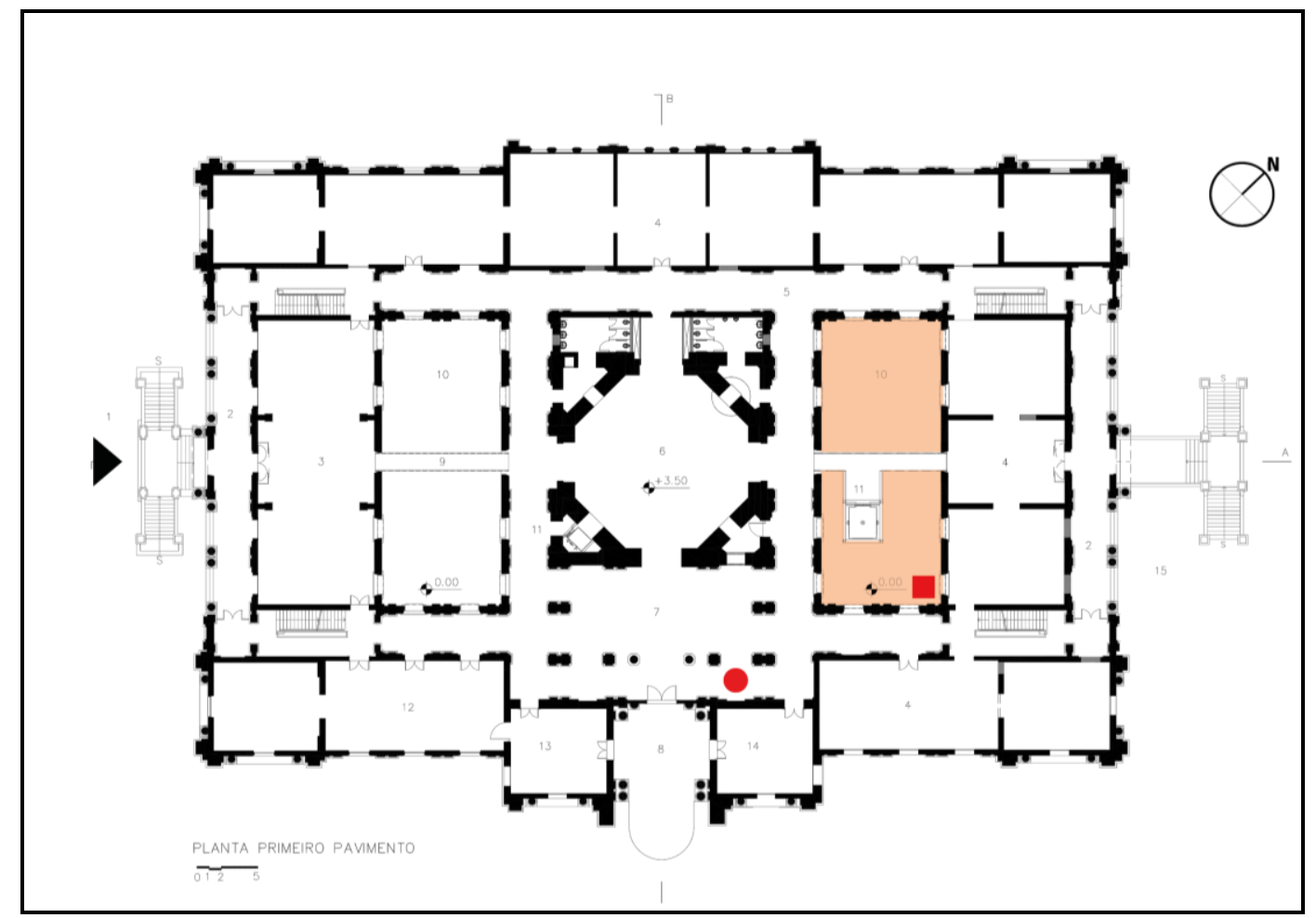

Figura 2 - Local do estudo de caso (bege), local de aplicação dos questionários de avaliação do ambiente virtual (círculo vermelho) e local de avaliação do ambiente construído (quadrado vermelho) Fonte: Elaborado pelo autor

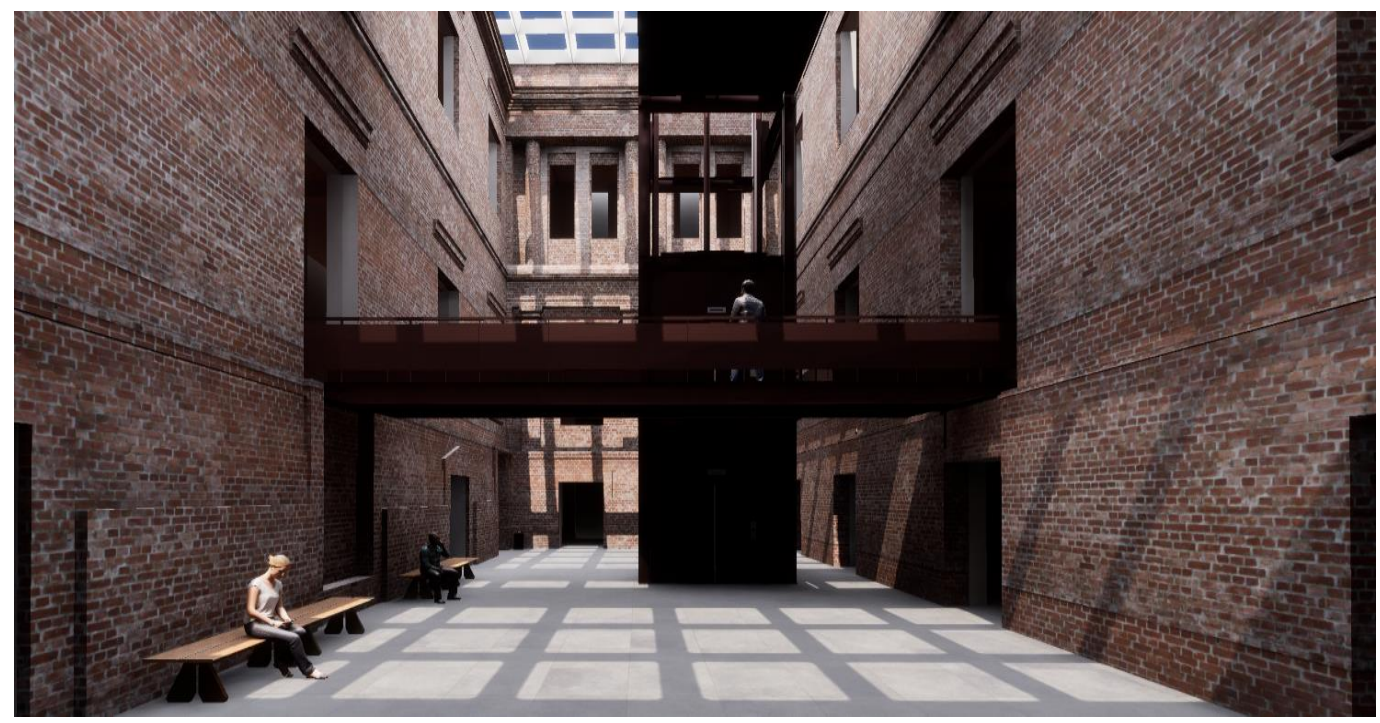

Figura 3 - Imagem inicial do ambiente virtual modelado -

Fonte: Desenvolvido pelo autor 
Na primeira etapa do levantamento in situ foi realizada no círculo vermelho (Figura 2). Uma vez aplicado o questionário de caracterização de público, os usuários participantes da pesquisa foram convidados a utilizar os óculos de Realidade Virtual, com ajuda do pesquisador e a responder perguntas de usabilidade imediata do DVA.

Essas perguntas tinham por objetivo avaliar o grau de conforto da ferramenta por usuários, importante para a possível inclusão deste equipamento nas dinâmicas de APP.

Em sequência, os usuários responderam a perguntas de avaliação da arquitetura vivenciada em ambiente virtual (Figura 3), segundo categorias de avaliação: dimensões e proporções, iluminação, materialidade e sensações de conforto e segurança. Este procedimento tinha a duração aproximada de 10 minutos.

A segunda parte do questionário foi realizada no Pátio Interno Norte da Pinacoteca, representada pelo quadrado vermelho da Figura 2, anterior. Neste local, os usuários responderam a um questionário de avaliação sobre o ambiente construído e em uso, a fim de comparação com o ambiente virtual. A duração deste procedimento foi de aproximadamente 5 minutos.

\section{DISCUSSÃO E RESULTADOS}

Como forma de avaliação da usabilidade do dispositivo, elemento integrante dos questionários aplicados, os resultados foram separados em dois eixos de análise: a primeira relativa à usabilidade "imediata" (primeiros segundos de utilização do equipamento) e "pós-uso" (após a aplicação do questionário de avaliação do ambiente virtual). Esses resultados, analisados de forma comparativa entre a aplicação do pré-teste e questionários finais, permite assumir algumas considerações, ainda que em caráter exploratório, acerca da utilização deste tipo de equipamento para a avaliação de projeto de arquitetura.

\subsection{Avaliação de usabilidade imediata do DVA}

Durante a aplicação do pré-teste, a avaliação de usabilidade do equipamento foi aferida, em geral, de forma positiva. Nesta amostra, $68 \%$ dos usuários afirmou que o uso do equipamento não havia causado nenhum desconforto nos primeiros segundos de utilização (Figura 4). Entre os possíveis tipos de desconforto, $24 \%$ alegou sentir tontura (Figura 4) e apenas $8 \%$ afirmou sentir dor de cabeça logo após a colocação dos óculos de Realidade Virtual (Figura 4). Sobre o conforto ergonômico do equipamento, $92 \%$ dos usuários respondeu que o equipamento se encaixava de forma confortável na cabeça (Figura 5) e a totalidade dos usuários afirmou que a projeção se apresentava nítida, sem quaisquer tipos de duplicidade de imagens ou falta de foco.

De forma comparativa, durante a aplicação dos questionários definitivos, os resultados apresentaram ainda maiores níveis de conforto imediatamente após a colocação dos óculos: $90 \%$ dos usuários alegou não ter qualquer tipo de desconforto, $8 \%$ afirmou ter tontura e apenas $2 \%$ alegou desorientação causada pelos óculos de Realidade Virtual (Figura 4). Quando questionados sobre o conforto ergonômico do equipamento, 99\% dos usuários afirmou que o aparelho se encaixava perfeitamente na sua cabeça (Figura 5). Por fim, em 
semelhança ao ocorrido na aplicação do pré-teste, a totalidade dos usuários afirmou que a projeção estava nítida e sem distorções. Esses dados demonstram, ainda que de forma experimental, que o dispositivo apresenta elevado nível de conforto à utilização, quando considerada a usabilidade imediata.
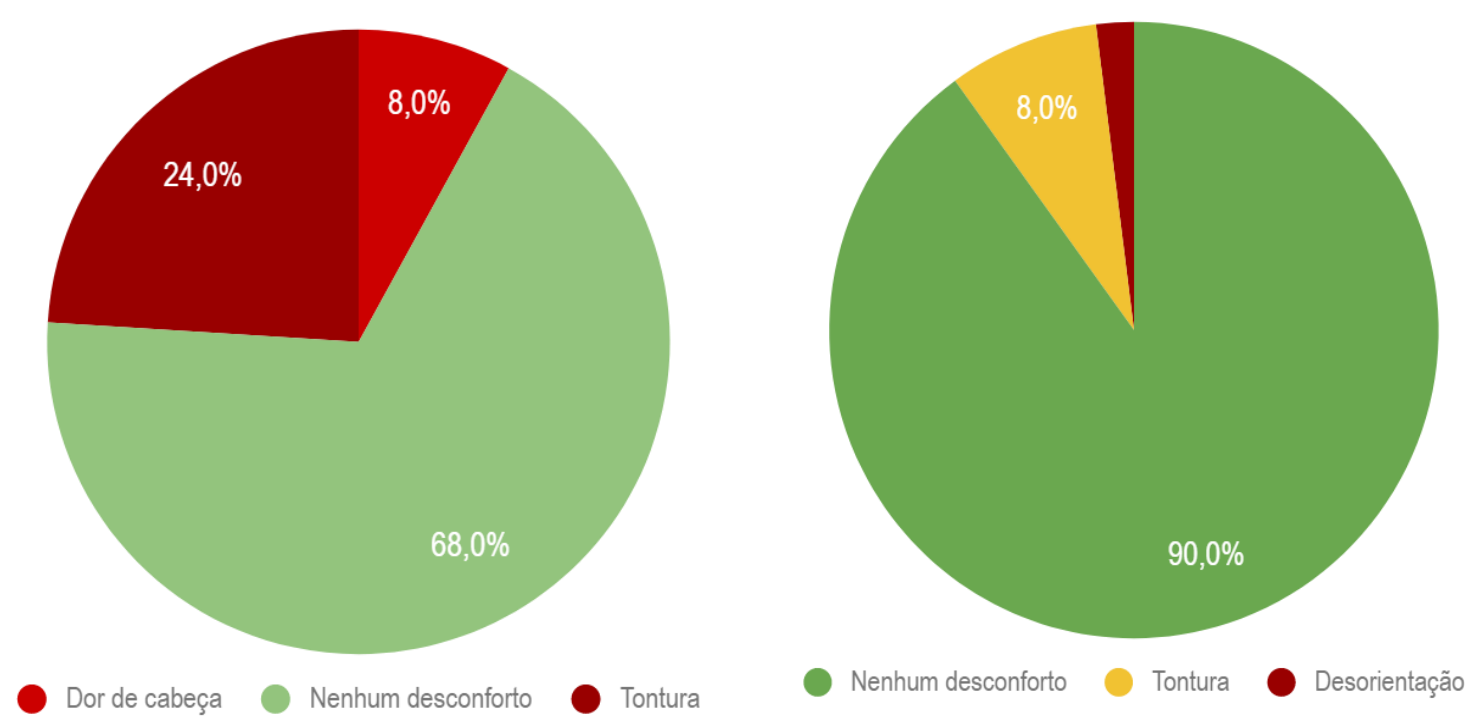

Figura 4 - Respostas à pergunta "Você sente algum tipo de desconforto?", aplicada durante o pré-teste (esquerda) e questionário definitivo (direita) Fonte: Desenvolvido pelo autor
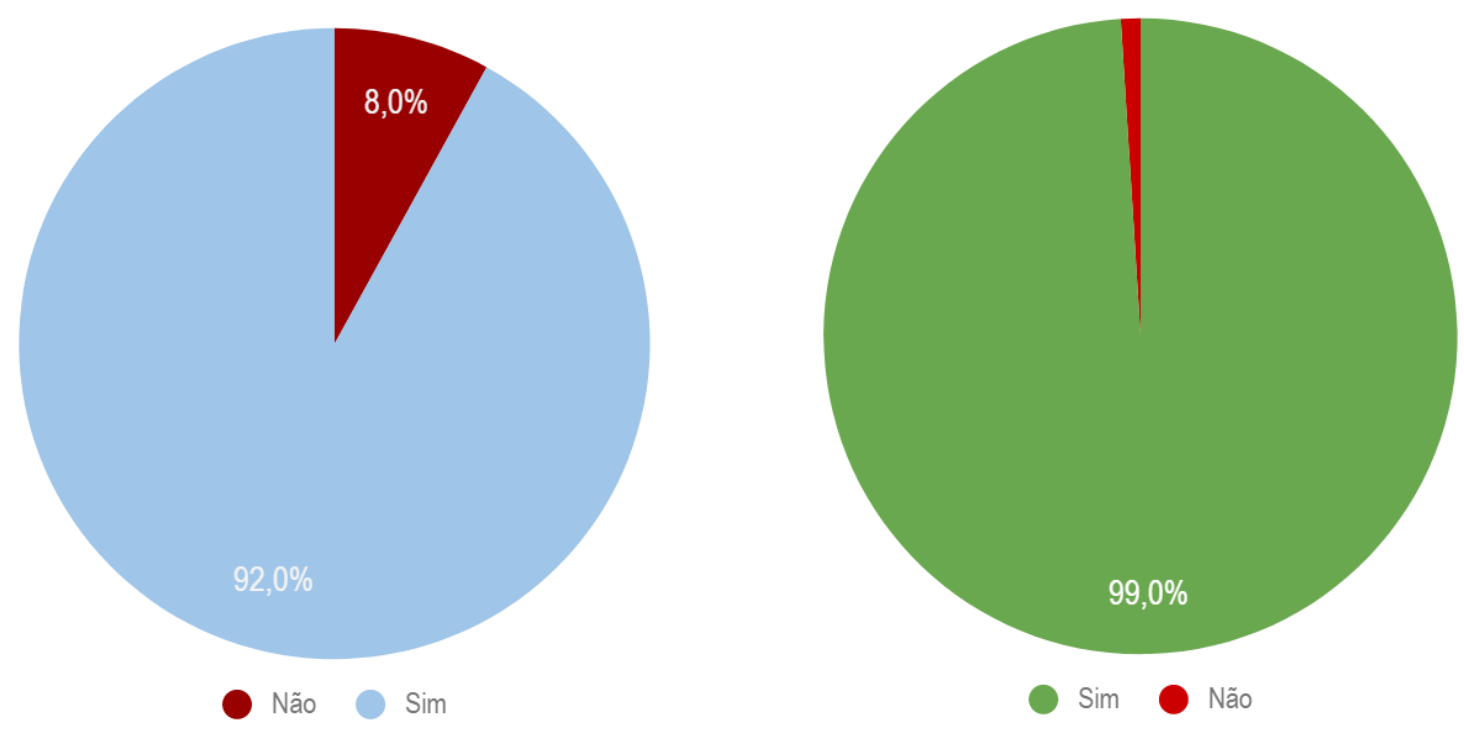

Figura 5 - Respostas à pergunta "O aparelho se encaixa de forma confortável na sua cabeça?", aplicada durante o pré-teste (esquerda) e questionário definitivo (direita) Fonte: Desenvolvido pelo autor 


\subsection{Avaliação de usabilidade do DVA pós-uso}

Ao final da aplicação dos questionários pré-teste, $64 \%$ dos usuários afirmou não possuir qualquer tipo de desconforto após a utilização dos óculos de Realidade Virtual, 28\% alegou ter tontura e $8 \%$ afirmou ter dor de cabeça (Figura 6). Quando questionados sobre 0 conforto ergonômico do equipamento, $80 \%$ dos usuários afirmou que o aparelho havia se encaixado de forma confortável após a utilização do equipamento durante a aplicação do questionário de avaliação do ambiente virtual (Figura 7). Sobre a qualidade da projeção, apenas $8 \%$ afirmou que a projeção não estava nítida após a finalização dos procedimentos (Figura 7).
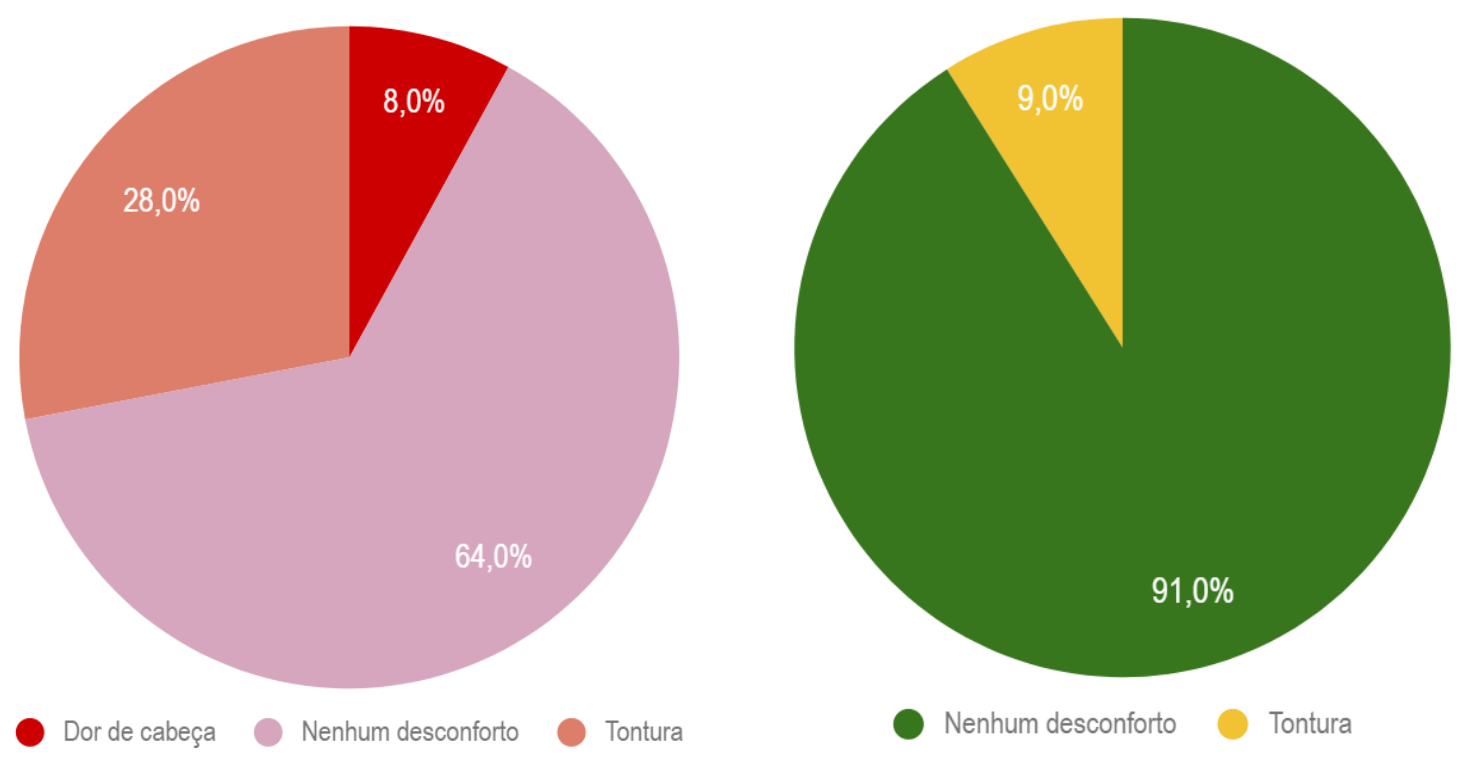

Figura 6 - Respostas à pergunta "Você sente algum tipo de desconforto?", aplicada durante o pré-teste (esquerda) e questionário definitivo (direita) -

Fonte: Desenvolvido pelo autor
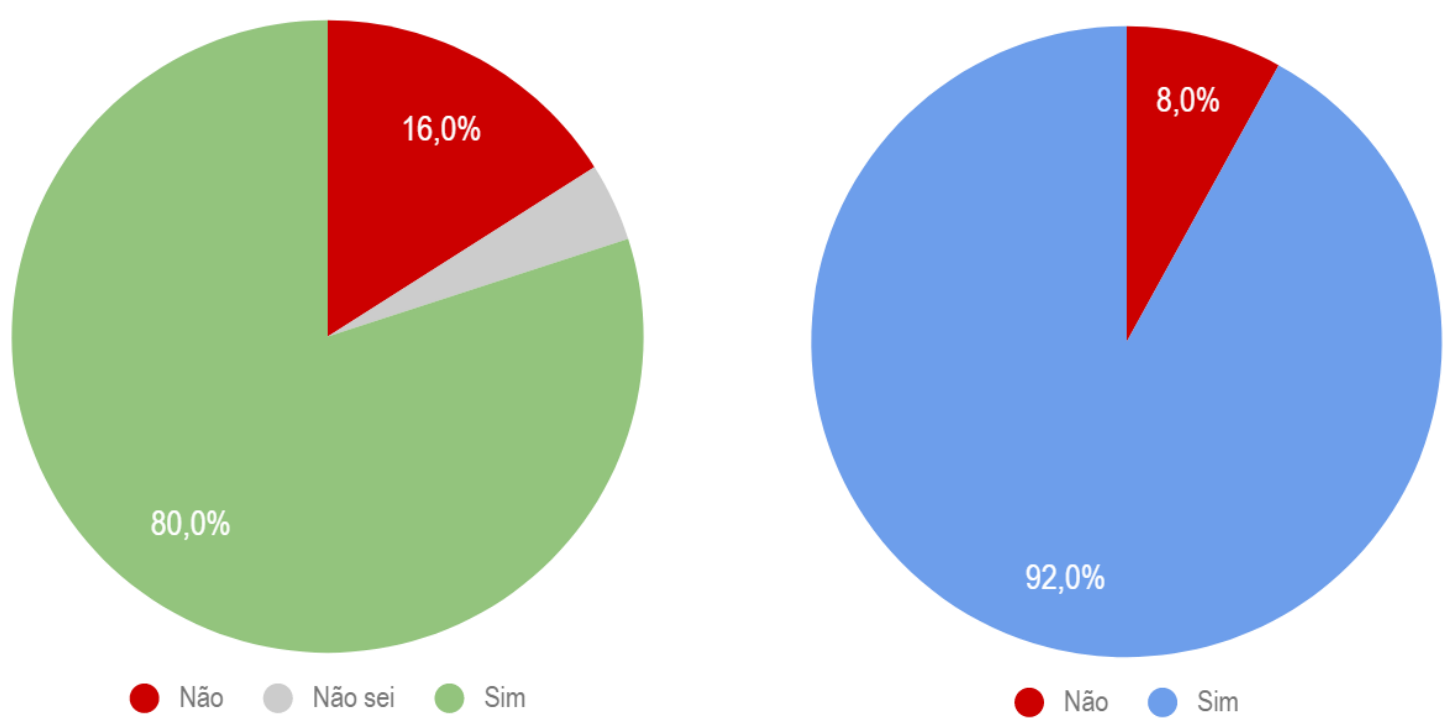

Figura 7 - Respostas à pergunta "O aparelho se encaixa de forma confortável em sua cabeça?", aplicada durante o pré-teste (esquerda) e questionário definitivo (direita) Fonte: Desenvolvido pelo autor 
Em comparação às mesmas perguntas aplicadas no questionário final, os níveis de conforto apresentaram significativo aumento: $91 \%$ dos usuários afirmou não ter qualquer tipo de desconforto após a utilização dos óculos de Realidade Virtual (Figura 6). Quanto às perguntas sobre conforto à utilização do dispositivo e à qualidade da projeção, as respostas foram positivas na totalidade dos casos, não apresentando qualquer caso de desconforto ou falta de nitidez na projeção.

Na avaliação do equipamento após o uso, portanto, houve aumento proporcional de $42 \%$ nos níveis de satisfação dos usuários do pré-teste em comparação aos usuários que responderam ao questionário final.

Comparando os resultados de usabilidade imediata e após a utilização do DVA para responder aos questionários definitivos, percebe-se que os níveis de conforto são semelhantes: $90 \%$ afirmou que não sentia qualquer desconforto imediatamente após a colocação e $91 \%$ afirmou que não sentia qualquer desconforto após a aplicação dos questionários, de duração aproximada de 10 minutos.

Entretanto, por mais que os números sejam semelhantes, apenas $8 \%$ (préteste)/2\% (questionários definitivos) dos usuários que apresentaram desconforto no início das atividades afirmou sentir desconforto também ao final das atividades, o que indica que cerca de metade dos usuários que apresentou desconforto com a utilização do dispositivo apresentou o desconforto no começo da sua utilização e a outra metade após a sua utilização por alguns minutos.

\section{CONCLUSÕES}

Os resultados até o momento obtidos na pesquisa, ainda que em caráter exploratório, permitem concluir alguns aspectos sobre a utilização de óculos de Realidade Virtual, a partir do uso do modelo Oculus Rift. Primeiramente, foi possível verificar que o equipamento, em geral, apresenta boa usabilidade a usuários que participam de processos de APP. Comparando as avaliações de usabilidade imediata no pré-teste e na aplicação dos questionários definitivos, constatou-se que houve aumento significativo dos níveis de conforto dos usuários.

Quanto à ergonomia do equipamento, houve aumento do nível de satisfação, mostrando que $O$ aparelho se encaixou confortavelmente em quase a totalidade dos usuários voluntários da pesquisa.

Entretanto, apesar de boa avaliação dos usuários em relação à usabilidade do equipamento, a tecnologia da Realidade Virtual, aqui avaliada por meio do DVA Oculus Rift, pode apresentar alguns empecilhos à utilização em larga escala durante o processo de projeto de arquitetura.

Alguns itens de menor influência foram citados por usuários que utilizaram os óculos de Realidade Virtual, como desconforto à utilização de máscara de proteção, necessária para a realização dos procedimentos com muitos usuários, e à presença de fios do DVA, que por vezes pode causar desconforto aos usuários. 
Do ponto de vista da modelagem, o isolamento do objeto de estudo (o pátio interno norte da Pinacoteca do Estado) também foi citado por poucos usuários como motivo de desconforto, pois, por mais que a modelagem se aproximasse do ambiente construído, a falta de contextualização do pátio, simulado apenas pela presença dos corredores perimetrais e das salas expositivas, causou estranhamento a alguns usuários que não conseguiam acessar outros ambientes do edifício da Pinacoteca.

Por fim, em relação à usabilidade do equipamento, muitos pré-requisitos de sistema o tornam de difícil utilização ampla durante os procedimentos de avaliação de projeto de arquitetura. Além disso, é necessário que drivers, software de modelagem e software do Oculus Rift, em constante processo de atualização, estejam atualizados para a utilização do equipamento. Por fim, a necessidade de utilização simultânea entre o software do DVA e de modelagem RV pode gerar desconforto à utilização do equipamento em larga escala na prática profissional de arquitetura. Conexão à internet e tomada para conexão com energia elétrica também são itens necessários à utilização do equipamento de forma satisfatória, o que o impede de ser utilizado em locais sem esta infraestrutura básica.

\section{AGRADECIMENTOS}

À Pinacoteca do Estado de São Paulo, pela autorização para a realização da pesquisa. Ao Conselho Nacional de Desenvolvimento Científico e Tecnológico (CNPq) pela bolsa produtividade concedida a Sheila Walbe Ornstein.

\section{REFERÊNCIAS}

BENEVENTE, V. Derivações da avaliação pós-ocupação (APO) como suporte para a verificação da aceitação de propostas habitacionais concebidas a partir de soluções espaciais e tecnológicas não usuais. Tese (Doutorado em Estruturas Ambientais e Urbanas) - Faculdade de Arquitetura e Urbanismo, Universidade de São Paulo, São Paulo, 2002.

FABRÍCIO, M. M.; ORNSTEIN, S. W (org.) Qualidade no projeto de edifícios. São Carlos: RiMa Editora, ANTAC, 2010.

ONO, R.; ORNSTEIN, S. W.; VILLA, S. B.; FRANÇA, A. J. G. L. Avaliação PósOcupação na Arquitetura, no Urbanismo e no Design: da teoria à prática. São Paulo: Oficina de Textos, 2018.

ORNSTEIN, S. W. Com os usuários em mente: um desafio para a boa prática arquitetônica? PARC Pesquisa em Arquitetura e Construção, Campinas, SP, v. 7, n. 3, p. 189-197, out. 2016. ISSN 1980-6809. Disponível em: <doi:http://dx.doi.org/10.20396/parc.v7i3.8647437>. Acesso em: 17 mar. 2017.

NOROUZI, N.; SHABAK, M.; EMBI, M.; KHAN, T. The architect, the client and effective communication in architectural design practice. In: Global

Conference on Business \& Social Science-2014. Kuala Lumpur: Elsevier, 2014. 
SOUZA, M. P.; IMAI, C.; AZUMA, M. H. Contribuições e limitações de modelos físicos e de realidade virtual na análise de projetos de HIS por usuários leigos. Gestão e Tecnologia de Projetos, São Carlos, v.13, n.3, p.21-37, dez. 2018.

VOORDT, T. J.M. van der; WEGEN, H. B.R. van. Architecture In Use. An introduction to the programming, design and evaluation of buildings. Amsterdam: Elsevier, 2005. 